\title{
Vehicle Induced Vibration on Real Bridge and Integral Abutment Bridge - A Short Review
}

\author{
Muhammad Khairil Ibrahim $^{\mathrm{a}}$, AzlanAbRahman ${ }^{\mathrm{b}}$, and BaderulHishamAhmad ${ }^{\mathrm{c}}$ \\ ${ }^{a}$ Department of Structure, Faculty of Civil Engineering, UniversitiTeknologi Malaysia, 81310 UTM \\ Johor Bahru, Johor, Malaysia \\ aimkhairil@gmail.com, bazlan@utm.my, cbaderul@utm.my
}

Keywords: Vehicle-Induced Vibration, Integral Bridge, Natural Frequency, Ambient Vibration

\begin{abstract}
Nowadays, vehicle-induced vibration is a subject matter interest in the bridge monitoring field. As compared to other types of excitation such as earthquake and accidental impact, the vehicle-induced vibration is often being less considered during the design process of the bridge. The newly implementedcode also does not emphasize on the vibration check for vehicular bridge and requires the engineers to refer to other "unnamed literature" if they would want to consider vibration check during the design process. However, in recent years there were few reported cases of road users experiencing the excessive vibration when they travelled on certain bridges, therefore raising concern among the bridge designer community the need for vibration check. This paper reviews several conducted researches on vehicle-induced vibration on the real bridge, the methodologies adopted and the outcome from each research. While there are extensive research been conducted on the real bridge, this review is limited to the conducted research into the different categories of bridges. Vehicle- induced vibration usually used for modal testing of the vehicular bridges and is chosen due to the flexibility offered by this method as type of excitation. Most of the researchers focused on the vibration by the vehicle of common bridge while less researches for the integral type. In the context of the integral bridge construction in Malaysia, bored pile is widely being used rather than H-type piles for integral bridges. Hence, there is a need for further exploration on the combination of integral type bridges with the bored pile foundation to assess their dynamic characteristics.
\end{abstract}

\section{Introduction}

Currently structural health monitoring is an emerging field inthe structural engineering due to the rapid development of monitoring equipment such as wireless transducer, lightweight signal analyzer, new operating system and etc. [1]. Previously, conducting Structural Heath Monitoring to real structure is quite a challenge, especially to an existing structure. As compared to newly built structure where the cable can be embedded in the structure during construction, setting up the monitoring system to the existing structure is complicated due to a lot of cables with various lengths and tagged which sometimes can ends up with confusing data port leading to error in interpretation of the data.

While other types of vibration are carefully taken into account such as seismic load, vehicle induced vibration not covered under the codedue to the nature of the vibration being considered 'relatively' small during the vehicle passing or stopped on the bridge. Most of the code of practicedoes not emphasize on this type of load[2, 3, 4]. These code normally requirean engineer to refer to 'unnamed' literature if there is a need to consider this type of load.

\section{Integral Bridge}

Integral bridge design is an innovation in bridge technology due its ability to cater for movement and the rotation of the whole structure, comparatively as conventional type of bridge where the movement and rotation are being tackled by expansion joint and bearing [5]. Considering the beneficial contribution of integral bridge, most of the design for simple bridges in Malaysia started to embark in this construction type since 2003. Integral bridge has been proven to be cost effective in term of construction as well as its overall lifespan [6]. 
Part of the problem is that, despite the simplicity of their construction, integral bridge are actually complicated structural systems. To thoroughly analyse a given structure, the designer must not only design for primary loads (dead, live, wind, etc.) but must also accurately account for secondary loads[7]. To additionally complicate the analysis, the response of a structure to a given set of external forces is very dependent on the geometry, materials, configuration, soil interaction, and construction details of the individual system.

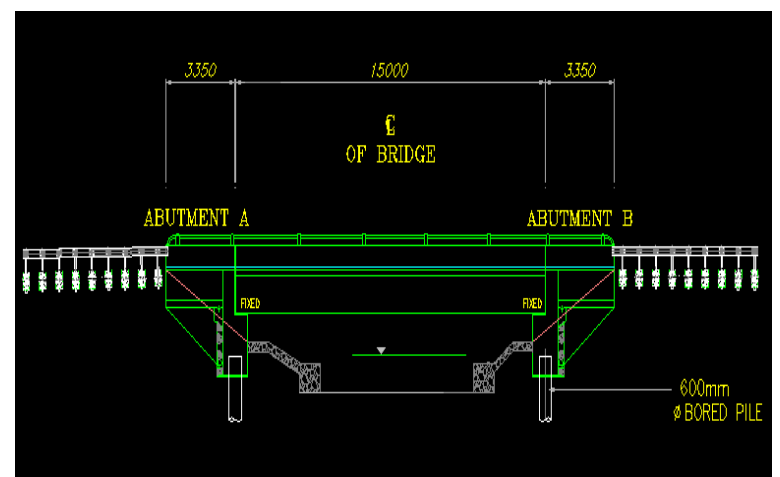

Fig 1. Side Elevation of 15 meter SgDamak Bridge [8]

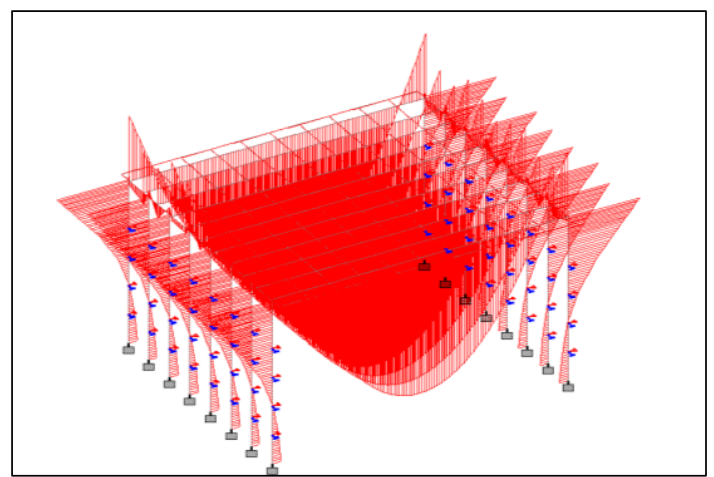

Fig 2. Typical bending moment of integral abutment bridge (SgDamak) due to self-weight [8]

\section{Modal Experiment}

Experimental modal analysis, or vibration system identification, has become an increasingly popular technique in recent years. Developments in measurement and instrumentation technology have facilitated the acquisition of data of sufficient accuracy to be submitted to the calculation procedures which constitute modal analysis, leading to extraction of the modal properties of a test structure, and thence to a mass and stiffness model of it [9].

\section{Excitation Method}

There are two types of vibration to excite the structure per se. Forcedexcitation e.g.Impact hammer, mechanical shaker and ambientexcitation [10,11]. Vehicle-induced vibration which falls under the ambient vibration categories with other type excitation e.g. Wind and other natural phenomena. Using vehicle as a mode of vibration is most commonly used type of excitation due to the availability of this method and ease of control as compared to other type of ambient vibration such as wind, flood etc. which are less predictable and measureable. This type of vibration also can be presented as normal load to be incorporated in the design process.

\section{Data Acquisition}

Data acquisition for the vehicle-induced vibration can be pretty fast and the results can be fairly accurate. Getting the vibration intensities can just be using the Vibro-meter while getting other dynamic parameters such as natural frequency, damping and stiffness requires a dynamic signal analyser, a set of accelerometers and extra computational work.

Due to the mass of the structure, bridges can be considered as a stiff structure, hence the capturing frequency can be set as low as $50 \mathrm{~Hz}[12]$ while most of the literature keeps the sampling frequency limit at $100 \mathrm{~Hz}[10,13]$. J. Matthew [14]using a sampling rate of $128 \mathrm{~Hz}$ andY. Wang [15] limit the capturing frequency at $200 \mathrm{~Hz}$. While the signal analyser can measure up to any frequency required, but it is wise to keep those limits of frequency at the expected frequency to minimise the storage capacity and lead to more accurate frequency capturing. 


\section{Natural Frequency}

Natural frequency is a frequency where a body naturally vibrate when it sets into motion without external force [15]. This type of frequency does give the interest matter for engineer either in mechanical or civil engineering due to the phenomena calledresonance. Resonance happens when there is a frequency induced by either by the forced or natural vibration coincides with the natural frequency.

The basic equation of natural frequency can be defined as below:

$$
f_{n}=\frac{1}{2 \pi} \sqrt{\frac{k}{m}}
$$

Where; $f_{\mathrm{n}}=$ natural frequency, $k=$ stiffness of the structure, $m=$ mass of the structure

S. Miao [9]proposed that the stiffness of the bridge can be assumed to remain constant due to the short period of excitation phase and data collection for each excitation.

\section{Ambient Vibration: Vehicle-Induced}

Among the first researchers who used this type of excitation were J.D. Turner and A.J. Pretlove[17] conducted the vibration test for single span bridge in Burghfield Lane Bridge in the year 1986 and found that the natural frequency of the bridge is $1.36 \mathrm{~Hz}$ for first mode and $6.13 \mathrm{~Hz}$ for the second mode.

S. Miaoet. al[10], studied on the traffic effect for multiple span concrete bridge in Holland and found that the natural frequency of $0.73-0.93 \mathrm{~Hz}$ for the first mode and $2.69 \mathrm{~Hz}$ for the second mode.

M. Reichenbachet. al[12]while conducting the test on energy harvester for bridge application, found that the natural frequency of a steel box girder bridge is $2.05 \mathrm{~Hz}$ and $4.15 \mathrm{~Hz}$ for first and second mode [11].

C.H. Chenet. al[13], used Random Decrement to obtain the free vibration phase and Ibrahim Time Domain (ITD) to extract modal characteristic from Koa Ping Hsi which is a suspension bridge. On site measurement of this bridge, gave the value of respectively $0.293 \mathrm{~Hz}, 0.561 \mathrm{~Hz}$ for the first and second mode with the damping value of 2.9 and 3.7.

Y. Wanget. al [15], found that the natural frequency of Voigt Bridge is $4.89 \mathrm{~Hz}$ for the first mode and $6.23 \mathrm{~Hz}$ for the second mode while conducting the studies on the wired and wireless application to evaluate the potential of the equipment on the Voigt Bridge.

T. Kakinumaet. al [18], conducted test for YammageBridge, which is a multi-span pre-stressed concrete bridge in order to evaluate the effectiveness of the Menshin design bridge and the rubber damping stiffness. As the natural frequency and damping ratio of the bridge is part of the objective, they found that the first mode of natural period occurred at 0.951 with the damping ratio of $14.3 \%$.

The test on integral bridge, conducted by M. J. Wheelanet. al[14] on single span concrete integral bridge, found that the natural frequency of the bridge is $9.5 \mathrm{~Hz}$ for the first mode and 11.09 for the second mode.

The research findings on frequency modes for different types of bridges from previous works are summarised in Table 1. 
Table 1- Type of bridge categories with frequency modes.

\begin{tabular}{|l|l|l|c|c|}
\hline \multicolumn{1}{|c|}{ Researcher } & \multicolumn{1}{|c|}{ Bridge } & \multicolumn{2}{c|}{ Type } & \multicolumn{2}{c|}{ Frequency (mode) } \\
\cline { 3 - 5 } & & & $1^{\text {st }}[\mathrm{Hz}]$ & $\begin{array}{r}2^{\text {nd }} \\
{[\mathrm{Hz}]}\end{array}$ \\
\hline $\begin{array}{l}\text { J. D. Turner\& } \\
\text { A.J. Prelove }\end{array}$ & Burghfield Bridge & Single Span Bridge & 1.36 & 6.13 \\
\hline S. Miaoet. al & Hollandse Bridge & Multiple Span Concrete Bridge & $0.79-0.93$ & 2.69 \\
\hline $\begin{array}{l}\text { M. } \\
\text { Reichenbachet. } \\
\text { al }\end{array}$ & Austin Bridge & Steel Box Girder Bridge & 2.05 & 4.15 \\
\hline $\begin{array}{l}\text { C. H. Chenet. } \\
\text { al }\end{array}$ & Koa Ping Hsi & Cable-Stayed & 0.293 & 0.561 \\
\hline Y. Wanget. al & Voigt Bridge & Box Girder Multi-span bridge & 4.89 & 6.23 \\
\hline $\begin{array}{l}\text { T. Kakimuraet. } \\
\text { al }\end{array}$ & Yaamage Bridge & Multiple Span Concrete Bridge & 1.052 & N.A \\
\hline $\begin{array}{l}\text { M. J. } \\
\text { Wheelanet. al }\end{array}$ & Wright Road & Single Span Integral Bridge & 9.5 & 11.09 \\
\hline
\end{tabular}

\section{Discussion}

In term of natural frequency, which is stiffness over the mass of the structure, we can see that the single span bridge type have higher value of natural frequencies. While this thing is an interestingpoint to note. Thesingle span bridges are normally being considered as very stiff structures, they tend to have higher natural frequency as compared to longer-span or multi-span bridges.

S. Miao et al. [10] and T. Kakimuraet. al. [18] found thatmulti-span concrete bridges have almost the same natural frequencies within the range of approximately $0.8 \mathrm{~Hz}-1.1 \mathrm{~Hz}$ for the first mode.For the case ofMulti-spanbox girder bridge, the natural frequency is relatively high because of the higher stiffness over mass due to the lighter segment of the bridge. While the same box girder type with different material as steel, the natural frequencies of $2.05 \mathrm{~Hz}$ and $4.15 \mathrm{~Hz}$ have been recorded. Steel by itself, usually having higher natural frequencies and it can be measured up to $1000 \mathrm{~Hz}$.

As for the integral bridge, the natural frequency is quite high where for the first mode indicates the value of $9.5 \mathrm{~Hz}$ and $11.09 \mathrm{~Hz}$ for the second mode. This is probably attributed to the flexibility of the $\mathrm{H}$ pile that has been adopted in the design of the bridge. The range of value providean interesting area of research in integral bridges where this type of bridge is currently being adopted in Malaysia. It is common local practice to use bored piles at abutment walls whereas in America and Europe it is more common to use steel H-piles in integral bridge construction.

Currently, the author conducting an initial study on the dynamic characteristic of the Integral Abutment Bridge with bored-piles in Malaysia.It is expected that the bored-pile construction would exhibit lower value of natural frequencies as compared to H-piles due to stiffer pile adopted. On the other hand, the natural frequencies of integral bridge should be higher compared to normal simply supported bridges because of the flexibility offered in the former.

\section{Acknowledgement}

The authors would like to express deep gratitude and thanks to the Ministry of Education viaTeknologi Malaysia for providing financial grant (Q.J130000.2617.10J31) and opportunity to carry out this research. 


\section{References}

[1] J.M. Ko, Y.Q. Ni, Technology developments in structural health monitoring of large-scale bridges,Engineering structures 27.12 (2005): 1715-1725.

[2] K.A.T.L. Kodikara, U.D. Morawaka, I.A.P.M.P. Gunathilake, C.S. Lewanagamage, Traffic Induced Vibration Analysis of Existing Steel Bridge in Padeniya-Anuradhapura Road, (2011), 3336

[3] British Standard Institution, Code of practice for design of concrete bridges. (BS 5400-4:1990)

[4] European Committee for Standardization, Design of concrete structures Concrete bridges. Design and detailing rules. (EN 1992-2:2005)

[5] J. H. Ahn, J. H. Yoon, J.H Kim, and S. H. Kim, Evaluation on the behavior of abutment-pile connection in integral abutment bridge. Journal of Constructional Steel Research 67(7), (2011), 1134-1148.

[6] M. DicleliandS. M. Albhaisi, Effect of cyclic thermal loading on the performance of steel Hpiles in integral bridges with stub-abutments. Journal of Constructional Steel Research, 60(2), (2004), 161-182.

[7] M. Dicleli, A rational design approach for prestressed-concrete-girder integral bridges. Engineering Structures, 22(3), (2000), 230-245.

[8] Public Work Department (2009), Design Report of SgDamak Bridge, Malaysia

[9] D. J. Ewins and P.T Gleeson, A method for modal identification of lightly damped structures. Journal of Sound and Vibration, 84(1), (1982), 57-79.

[10] S.Miao, A.Knobbe, E.Koenders, andC. Bosma, Analysis of Traffic Effects on a Dutch Highway Bridge, Proceeding of International IABSE Conference, (2013),357-364.

[11] O.S. Salawu and C. William, Review of full-scale dynamic testing of bridge structures, Engineering Structures 17.2 (1995): 113-121.

[12] M. Reichenbach, J. Fasl, V.A. Samaras, S. Wood, T. Helwig, and R.Lindenberg,Evaluating vehicular-induced bridge vibrations for energy harvesting applications,PIE Smart Structures and Materials + Nondestructive Evaluation and Health Monitoring. International Society for Optics and Photonics, (2012), 83472E-83472E.

[13] C. H. Chen, Y. Y. Lin, and S.C. Yang, Variability of Dynamic Characteristics of a CableStayed Bridge Subject to Traffic-Induced Vibrations, Journal of C.C.I.T 39,(2010),47-56.

[14] M. J. Wheelan, M. V. Gangone, K. D. Janoyan, and R. Jha,Real-time wireless vibration monitoring for operational modal analysis of an integral abutment highway bridge. Engineering Structures, 31(10), (2009), 2224-2235

[15] Y. Wang, K. J.Loh, J. P. Lynch, M. Fraser, K. H. Law, and A. Elgamal, Vibration monitoring of the Voigt Bridge using wired and wireless monitoring systems, Proceedings of the 4th ChinaJapan-US Symposium on Structural Control and Monitoring, (2006), 16-17.

[16] R.R. Craig, A. J. Kurdila, Fundamental of Structural Dynamic,(John Wiley and Sons) (2011)

[17] J. D. Turner, and, A. J.Pretlove, A study of the spectrum of traffic-induced bridge vibration. Journal of Sound and Vibration 122 (1988), 31-42.

[18] T. Kakinuma, K. Kawakami, K. Kumakura, H.Tani, N. Abe, Proceedings of Third U.S.- Japan Workshop on Earthquake Protective System for Bridges, (1994) 3-10 